\title{
Evidence for the Syntactic Diversity of Numeral Classifiers
}

Peter Jenks (Harvard University)

pjenks@fas.harvard.edu

\section{Introduction}

This paper examines whether numeral classifiers are always functional heads projected by nouns, as claimed by Borer (2005) and Simpson (2005). Contra to their claims, this paper will posit that classifiers are not structurally uniform crosslinguistically; they can either head functional projections of the noun or form a constituent with the quantifier, adjoining to NP.

The evidence for this claim is that certain syntactic constructions are correlated with the order of quantifier-classifier $(\mathrm{Q})$ relative to the lexical common noun $(\mathrm{N})$ :
a. $\quad$ Clf-N only occurs in QN languages ( $(4)$.
b. Quantifier Float only occurs in NQ languages ( $\$ 5)$.

I will argue that each of these constructions follow from the different syntactic structures for extended NPs (xNPs).

\section{The Syntax of Numeral Classifiers}

Nouns in classifier languages have general number (Corbett 2000), meaning they can be interpreted as singular or plural. The obligatory occurrence of classifiers with numerals may be tied to general number, as in Greenberg (1975) and Rullman \& You (2006) or an equivalent concept, such as the idea that common nouns in classifier languages have a kind denotation (Chierchia 1998).

Inspired by parallels with clause structure, Tang (1990) proposed that classifiers head a functional projections of $\mathrm{N}$ :

\section{(2) $\left[\mathrm{ClfP}\right.$ QP $\left[\mathrm{Clf}^{\prime}\right.$ Clf $\left.[\mathrm{NP} N]\right]$}

Following this claim, Borer (2005) and Simpson (2005) propose that a similar structure — where $\mathrm{Q}$ is also a functional head - is universal, even if the QN order is not transparently reflected on the surface.

While classifiers are selected by a quantifier, nouns and classifiers are not always adjacent. Thus, the structures below, where the ClfP is a kind of measure phrase, are logical alternatives (cf. Ionin \& Matushansky 2006, ex. 22a):

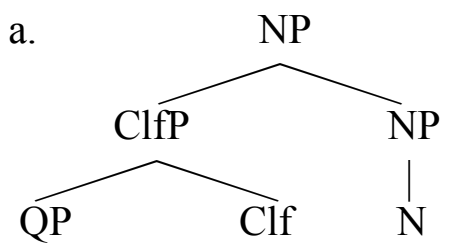

b.

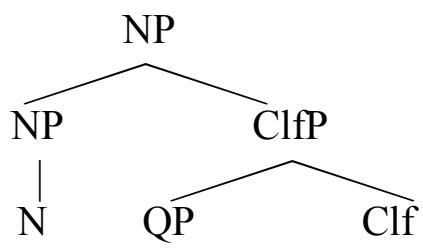

Here, Q and Clf form a constituent and adjoin to NP (or some higher projection of NP).

The proposal in this paper is that the difference between (1) and (2) is the whether the classifier c-selects the NP, and that it is strongly correlated with word order: 
(4) a. If it has the structure in (2), then a language has [Q-Clf]-N surface order.

b. If a language has N-[Q-Clf] surface order, then it has the structure in (2b).

c. Languages with multiple orders vary between (2a) and (2b).

In the sense that these structures are distinct, this data corroborates the findings of Simpson (2005), who proposes surface structures which are similar in constituency (§6).

\section{Generalizations about the word order typology of numeral classifiers \\ Quantifiers precede classifiers \\ regardless of headedness across \\ languages, accounted for by their \\ position in [Spec, ClfP] $(2,3)$. In \\ contrast, Q can either precede or follows N (Green- berg 1975, Jones 1970). The distinction between QN and NQ does not correlate with the genetic affiliation (Table 1). Furthermore, if a language is QN, then it is \\ - Sino-Tibetan o Mon-Khmer \\ - Hmong-Mien \\ - Kra-Dai \\ - Altaic} head-initial (Table 1). And, most crucially for our purposes, the distinction between QN vs. NQ correlates with Clf-N and Q-float (Table 1).

Geographically, the distribution of QN vs. NQ

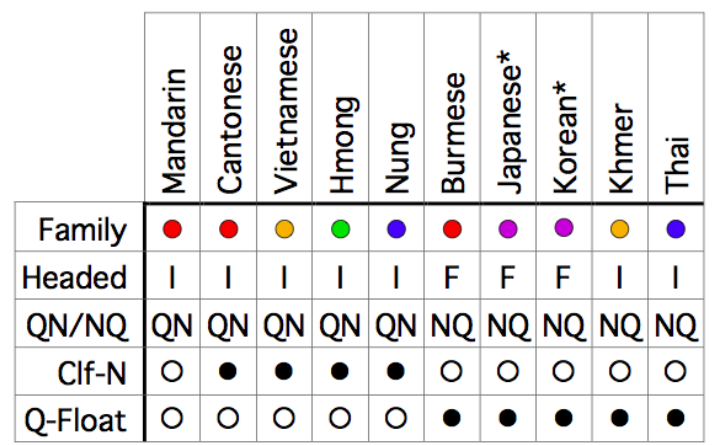

Table 1: Word order, quantifier float, and Clf-N

*Korean and Japanese also allow the QN order. Hence, "NQ" above should be interpreted as "allowing the NQ order."

is areal (Figure 1), though NQ languages do form a geographically discontinuous region, with Japan and Korean as representatives to the north.

Below are examples of each word order:

$\begin{array}{lc} & \text { QUANTIFIER-NOUN } \\ \text { ba-cây } & \text { bùt } \\ \text { 3-ClF } & \text { pen }\end{array}$

(6)

$\begin{array}{ll}\text { san-ben } & \text { shu } \\ \text { 3- CLF } & \text { book }\end{array}$

$\begin{array}{llr}\text { ib-tus } & \text { tub.txib } & \text { (Hmong) } \\ \text { 1- CLF } & \text { messenger } & \text { (Bisang 1993, ex. 6) }\end{array}$

\begin{tabular}{|c|c|c|}
\hline \multicolumn{2}{|c|}{ NOUN-QUANTIFIER } & \multirow[b]{2}{*}{ (Thai) } \\
\hline này.stŭt & săam-lêm & \\
\hline book & 3- CLF & \\
\hline hon & san-satsu $(=0)$ & (Japanese) \\
\hline book & 3-CLF (=ACC) & \\
\hline zəbwe & $\theta$ õù-lõù & (Burmese) \\
\hline table & $3-\mathrm{CLF}$ & \\
\hline
\end{tabular}

(Vietnamese)

(Nguyen 2004, ex. 1)

(Mandarin)

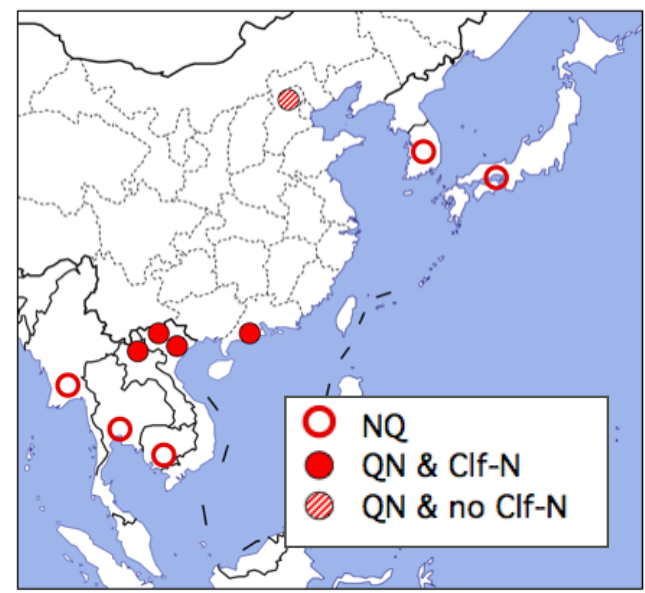

Figure 1: Distribution of $Q N$ vs. NQ 


\section{Numeral classifiers without numerals}

In many QN languages, classifiers occur without a numeral, the Clf-N construction. Clf$\mathrm{N}$ in subject position must be interpreted as definite (see also Simpson 2005):
a. Cuổn sách hay lấm.
CLF book interesting very
'The book is very interesting.'
b. Tôi muõn mua cuổn sách.
I want buy CLF book
'I want to buy a/the book.'

(Vietnamese)

(Nguyen 2004, p. 17)

Clf-N is always singular. Plurality is marked differently in different languages, either with a plural determiner (12), or by substituting a plural classifier (13):

$$
\begin{array}{llll}
\text { các } & \text { cón } & \text { ngựa } & \text { đen } \\
\text { PL } & \text { CLF } & \text { horse } & \text { black }
\end{array}
$$

'the black horses'

(Vietnamese, Nguyen 2004, p. 18) $\begin{array}{ll}\text { gaa/di } & \text { ce } \\ \mathrm{CLF} / \mathrm{PL} & \text { car }\end{array}$

'the car/the cars'

(Cantonese, Cheng \& Syb. 1999, ex. 18)

Other languages exhibit more "inflectional" classifier systems; Weining Ahmao and Wu Chinese mark (in)definiteness on the classifier with tone (Gerner \& Bisang 2008, Cheng \& Sybesma 2005). Like articles, which also mark number and definiteness, these classifers can be analyzed as taking NP complements, as in (2). NQ languages have no equivalent, N-Clf, construction, which indicates that nouns are not selected by classifiers in these languages.

\section{Numeral classifiers and quantifier float}

Languages in Table 1 with the NQ order also allows quantifier float (QF) to adverbial positions, shown below for Thai:

$\begin{array}{lll}\text { Nák-riian }_{\mathrm{i}} & \text { Paan này.sǔu } & \text { thúk-khon }_{\mathrm{i} .} \\ \text { student } & \text { read book } & \text { every-CLF }^{\text {person }} \\ \text { 'Every student read a book.' } & \end{array}$

Benmamoun (1999, also Doetjes 1998) shows that QF in Arabic involves a $Q$ that is an independent $\mathrm{xNP}$. He proposes that this $\mathrm{xNP}$ always an adjunct, whether to the NP, as in (3), or to the clause

Likewise, Thai QF seems to involve syntactically independent Qs:
Dèk $_{\mathrm{i}}$ klàp bâan wan.níi $[\mathrm{CP}$
phûta-thîi-cà? $\mathrm{PRO}_{\mathrm{i}}$ child return home today in.order.to
tham kan.bâan thúk-khon ${ }_{\mathrm{i}}$ phrûy.níi.] every- CLF ${ }^{\text {perso }}$ tomorrow
do homework (Thai)
'The children went home today to all do their homework tomorrow.'

In (13) the floated Q is embedded in an adjunct island while its antecedent NP is in the main clause, see Jenks (2010) for more arguments. As in Arabic, floated Qs in Thai are syntactically 
independent from NP. The presence of FQ in NQ languages, then, is unsurprising if the NQ order always inlvoves independent $\mathrm{Qs}$, as in (2b).

\section{An alternative}

Simpson (2005) generates the NQ order from (1) via NP-movement under the assumption that classifiers are always functional projections. Recall that classifiers only behave as articles in QN languages. We could account for the complementarity between the Clf-N construction (or NClf) and NQ order with a $[\mathrm{uN}]$ feature on $\mathrm{D}^{0}$ that is satisfied by $\mathrm{Clf}^{0}$-to- $\mathrm{D}^{0}$ or NP-to-DP:
a. [DP $\left.\left.\mathrm{Clf}_{\mathrm{i}}\left[\mathrm{ClfP} t_{\mathrm{i}}[\mathrm{NP} \mathrm{N}]\right]\right]\right]$
Clf-to- $D$ (for QN)
b. $\left[\mathrm{DP} \mathrm{NP}_{\mathrm{i}}\left[\mathrm{D}^{\prime} \mathrm{D}\left[\mathrm{ClfP} \mathrm{QP}\left[\mathrm{Clf}, \mathrm{Clf} t_{\mathrm{i}}\right]\right]\right]\right.$
$N P$-to- $D P$ (for NQ)

Simpson's approach would mesh with analyses of QF as Q-stranding by NP-movement (Miyagawa 1989, Sportiche 1989). Yet we have already seen a problem for this view is (13), which indicates that such an approach is problematic in accounting for QF in Thai.

\section{Conclusions}

Generalizations about classifier syntax based purely on word order point towards particular syntactic structures. QN languages can have a Clf-N construction, where the classifier is a funtional projection of the noun, indicating that (1) is their structure. NQ languages allow QF, indicating that Q-Clf is a constituent in these languages to the exclusion of the noun, as in (2).

Acknowledgments For valuable discussion, thanks to Gennaro Chierchia, Amy Rose Deal, James Huang, Clemens Mayr, Hiroki Narita, Masao Ochi, audiences at the CUNY Grad Center, Dartmouth College, and the Harvard/MIT Fall 2009 course on East Asian Linguistics, and especially Maria Polinsky. Thanks also to Saowanee Deetayat and Pittayawat Pittayaporn for their help with Thai, Winmar Way with Burmese, Solay with Khmer, and Daniel Kaufman with Indonesian. Any errors are my own.

References: Benmamoun, E. 1999. The syntax of quantifiers and quanitifier float. Linguistic Inquiry 30, $621-642$. Borer, H. 2005. In Name Only. Oxford, Oxford University Press. Bisang, W. 1993. Classifiers, quantifiers, and class nouns in Hmong. Studies in Language 17, 1-51. Cheng, L. \& R. Sybesma. 1999. Bare and not-so-bare nouns and the structure of NP. Linguistic Inquiry 30, 509-542. ---. 2005. Classifiers in four varieties of Chinese. In Cinque \& Kayne. Chierchia, G. 1998. Reference to kinds across languages. Natural Language Semantics 6, $339-405$. Corbett, G. 2000. Number. Cambridge: Cambridge University Press. Cinque, Guglielmo. 2005. Deriving greenberg's universal 20 and its exceptions. Linguistic Inquiry 36:315-332. Doetjes, J. 1998. Quantifiers and Selection: On the Distribution of Quantifying Expression in French, Dutch, and English. HIL Dissertations 32 . The Hague: Holland Institute of Generative Linguistics. Gerner, M. \& W. Bisang. 2008. Inflectional speaker-role classifiers in Wiening Ahmao. Journal of Pragmatics 40, 719-732. Greenberg, J. 1975. Dynamic aspects of word order in the numeral classifier. In Word order and word order change, C. N. Li (Ed.), 27-46. Austin, TX: University of Texas Press. Ionin, T. \& O. Matishansky. 2006. The composition of complex cardinals. Journal of Semantics 23, 315-360. Jenks, P. 2010 Floating quantifiers in Thai without stranding. Ms., Harvard University. Jones, R. B. 1970. Classifier constructions in Southeast Asia. Journal of the American Oriental Society 90, 1-12. Miyagawa, S. 1989. Structure and case marking in Japanese. New York: Academic Press. Nguyen, T. H. 2004. The structure of the Vietnamese noun phrase. PhD Diss., Boston U. Rullman, H. \& A. You. 2006. General number and the semantics and pragmatics of indefinite bare nouns in Mandarin Chinese. In Where semantics meets pragmatics, Klaus von Heusinger and Ken P. Turner (Eds.), 175-196. Amsterdam: Elsevier. Saito, M, K. Murasugi, \& T.-H. J. Lin. 2009. N'-ellipsis and the structure of noun phrases in Chinese and Japanese. Journal of East Asian Linguistics 17: $247-271$. Simpson, A. 2005. Classifiers and DP structure in Southeast Asia. In Cinque \& Kayne. Sportiche, D. 1989. A theory of floating quantifiers and its corollaries for constituent structure. Linguistic Inquiry 19, 425-449. Tang, C.C. J. 1990. A note on the DP analysis of the Chinese noun phrase. Linguistics 28, 337-354. 